\title{
Oral Cavity Squamous Cell Carcinoma Comparitive Evaluation on Computed Tomography and Magnatic Resonance Imaging
}

\section{Sangeeta Saxena ${ }^{1}$, Abhishek Gupta ${ }^{2}$, Dharmaraj Meena ${ }^{3}$, Harshvardhan Khokhar ${ }^{4}$, Bhajan Lal' ${ }^{2}$, Chandraveer Godara ${ }^{2}$}

${ }^{1}$ Senior professor, Department of Radio-diagnosis, Government Medical College, Kota, Rajasthan, INDIA, ${ }^{2}$ Resident doctor, Department of Radio-diagnosis, Government Medical College, Kota, Rajasthan, INDIA, ${ }^{3}$ Professor \& HOD, Department of Radio-diagnosis, Government Medical College, Kota, Rajasthan, INDIA, ${ }^{4}$ Assistant professor, Department of Radio-diagnosis, Government Medical College, Kota, Rajasthan, INDIA.

\section{Abstract}

Background: Cancers are the most common cause of death in adults. Oral cancer is any malignant neoplasm which is found on the lip, floor of the mouth, cheek lining, gingiva, palate or in the tongue. Oral cancer is among the top three types of cancers in India. In India most of the (nearly 90-95\%) oral cancers is squamous cell carcinoma. Aim of our study is to detect the Pattern of tumor spread and contribution of CT and MRI in staging of oral cavity. Subjects and Methods: In this prospective study we studied 46 patients after proper informed and written consent. Clinical complaints were recorded along with other relevant demographic data. Each patient underwent CT scan and MRI. Results of radiological investigations were correlated with Histopathology. Imaging modalities were used in tumor staging, cervical lymph nodes assessment, bone (mandible) invasion \& muscles of tongue invasion. Results: We have observed that Oral cavity SCC is more common in the age group of 51-60 years, with male is to female ratio 1.71. Most common location is buccal mucosa and most common risk factor is tobacco chewing. CT scan is less sensitive $(67.39 \%)$ modality than MRI scan $(84.78 \%)$ in detection of primary tumor stage; whereas no significant statistical difference is observed in CT and MRI for cervical lymph nodes detection. In detection of mandibular invasion MRI is more sensitive $(80.01 \%)$ but equally specificity $(92.31 \%$ ) than to CT scan (sensitivity $68.42 \%$ \& specificity $88.89 \%$ ). For muscle of tongue invasion MRI is more sensitive and specific $(89.47 \%$ \& $88.89 \%$, respectively) than to CT (sensitivity is $50.01 \%$ \& specificity is $92.31 \%$ ). Conclusion: CT and MRI are nearly similar in assessing cervical node metastasis. For bone invasion MRI is a superior over CT in our study, but this difference is not significant. MRI was considered superior to CT scan in evaluating the primary tumor extent and muscle of tongue infiltration with significant statistical difference.

Keywords: Oral Cavity, Squamous Cell Carcinoma.

Corresponding Author: Dr. Abhishek Gupta, Resident doctor, Department of Radio-diagnosis, Government Medical College, Kota, Rajasthan, India.

Received: May 2019

Accepted: June 2019

\section{Introduction}

\section{GLOBOCAN 2018 Data (India data):}

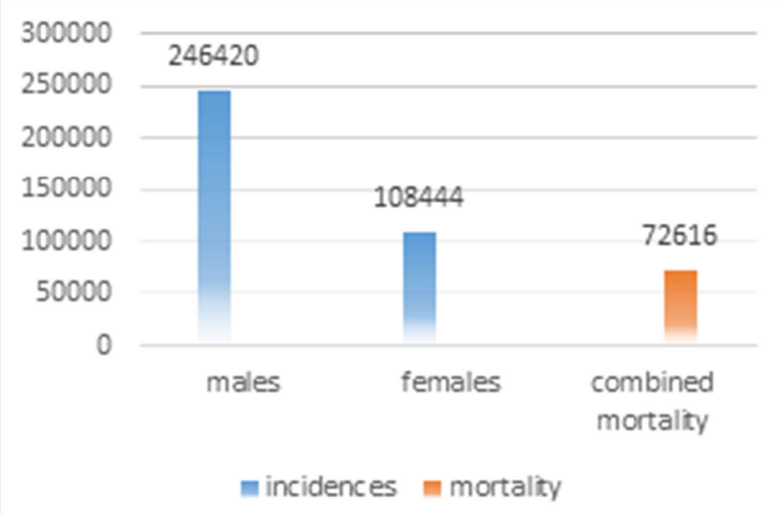

Figure 1: The incidence of oral cavity cancer and mortality in males and females in India

Oral cancer is among the top three types of cancers in
India. ${ }^{[1]}$ India has one third of oral cancer cases in the world. ${ }^{[2]}$ According to globocan2018 data Indian incidence have 119,992 new cases (males: 92011 \& females: 27981), out of which mortality is 72,616 . In general, more men suffer and die from oral cancer than women.

\section{GLOBOCAN 2018 DATA (Global data):}

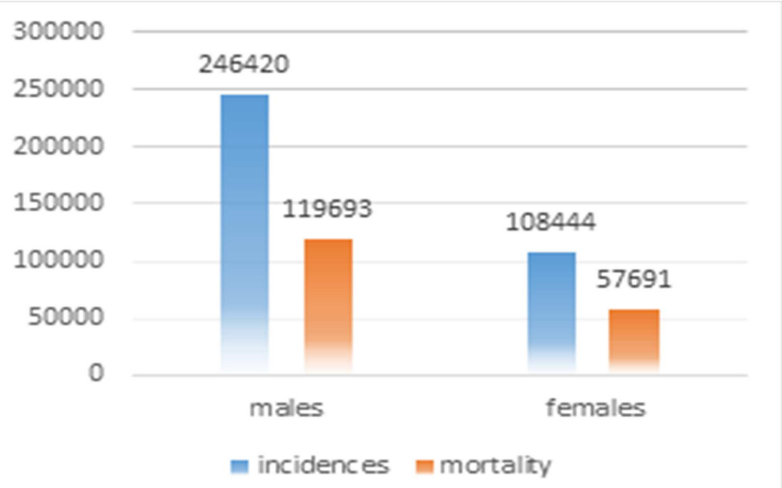

Figure 2: The global incidence of oral cavity cancer and mortality in males and females 
According to the Globocan2018 data, the global incidence of oral cavity cancer is 354,864 and total mortality is 177,384 ; in which incidences in male population is 246,420 and in female population 108,444; \& mortality in male population is 119,693 and in female population is 57,691 .

Considering the gender in all the age groups, men are more affected than women. In India, men are two to four times more affected than women due to the changes in the behavioral and lifestyle patterns. Cancer of buccal mucosa is the most common site of oral cancer and the other common site is tongue and gingiva. Oral cancer is considered to be a disease which occur in elderly people. However, most of the oral cancer cases occur between ages of 50 to 70 years, but it could also affect children as early as 10 years. Incidence of oral cancer increases by age. ${ }^{[3]}$

Low social economic class is interrelated with factors like nutrition, health care, living condition and risk behaviors which contributes to the development of oral cancer. ${ }^{[4]} \mathrm{A}$ case control study from India demonstrates that oral cancer is interrelated with low incomeMostly it is diagnosed at later stages which result in low treatment outcomes and high costs. Hence the delay is largely associated with advanced stages of oral cancer. Earlier detection of oral cancer offers the best chance for long term survival and has the potential to improve treatment outcomes and make healthcare affordable. ${ }^{[4]}$

Tobacco consumption habit among the patients either as smokeless tobacco 'GUTAKA' or smoking, alcohol consumption are the common causes for oral cancer. ${ }^{[5]}$ Positive family history of oral cancer, viral infections like HPV, poor oral hygiene are the other causes for oral cancer. Also some precancerous conditions are associated with increased incidences of oral cavity tumors eg: Erythroplakia, Leukoplakia (particularly: Erythroleukoplakia, Proliferative verrucous leukoplakia), Actinic cheilitis, Lichen planus etc.

\section{Subjects and Methods}

From July 2017 to December 2018, we collected 46 juxtaoral malignant tumor cases, Out of these 29 were men and 17 were women. All the cases aged from 28 to 92 years and the mean age was 56 years old. including 22 cases of buccal mucosa carcinoma (CA), 14 cases of tongue CA, 5 cases of retro molar trigone $\mathrm{CA}, 3$ cases of floor of mouth $\mathrm{CA}$ and 1 case of hard palate CA and 1 case of lip CA. In all patients, clinical complaints were recorded along with other relevant demographic data. Each patient underwent CT scan and MRI. Results were correlated with Histopathology. Imaging modalities were used for tumor staging, cervical lymph nodes assessment, bone (mandible) invasion \& muscles of tongue invasion.

\section{Inclusion Criteria}

All patients with clinically diagnosed oral cavity tumors (oral cavity includes the anterior two thirds of the tongue, the hard palate, the floor of mouth, the buccal mucosa and the gingiva.)

\section{Exclusion Criteria}

Patients with Recurrent/treated tumors, oropharynx and hypo pharynx tumors, severely debilitated patient with renal impairment and Allergic to contrast media.

The CT examinations in our cases were performed with CT scanner after $100 \mathrm{ml}$ contrast medium IV injection. The scanning planes included axial scan with $4 \mathrm{~mm}$-slice thickness for oral cavity from skull base to hyoid bone and $8 \mathrm{~mm}$-slice thickness for neck. The coronal scan was also performed with $4 \mathrm{~mm}$-slice thickness in some cases. Both soft tissue and bone window setting were displayed for evaluation of soft tissue extension and bony invasion.

The MRI of oral cavity was performed with $1.5 \mathrm{~T}$ MRI scanner (PHILLIPS ACHEIVA) superconductive whole body MR scanner.

The CT and MRI imaging data were evaluated for the tumor border delineation, cervical lymph nodal status, bony invasion and floor of tongue muscles. The T-staging of CT and MRI were recorded according to American Joint Committee on Cancer (AJCC-8) criteria. After imaging study, the patients received operation for tumor resection. The pathological $\mathrm{T}$-staging was also recorded according to the pathological findings under AJCC criteria.

\section{Statistical analysis}

Descriptive and Inferential statistical analysis has been carried out in the present study using computer software (SPSS Trial version 23 and primer). The qualitative data were expressed in proportion and percentages, and the quantitative data expressed as mean and standard deviations. The difference in proportion was analyzed by using chi square test. Significance level for tests were determined as 95\% $(\mathrm{P}<0.05)$. The diagnostic accuracy, sensitivity, and specificity of the various imaging modalities were calculated.

\section{Results}

We have observed that Oral cavity SCC is most common in the age group of 51-60 years with 13 patients (28.26\%) and age distribution is from minimum age 28 years and maximum age 91 years, with male is to female ratio 1.71 . Most common location for malignant lesion in oral cavity is buccal mucosa in 22 patients $(47.82 \%)$ and most common risk factor is tobacco chewing in 35 patients $(76.08 \%)$. Well differentiated SCC is most common histological grade.

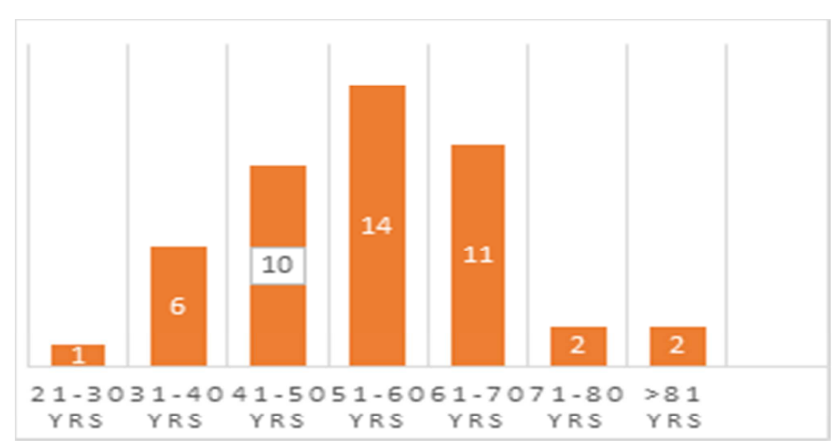


Figure 3: Bar chart showing age distribution of patients in our study

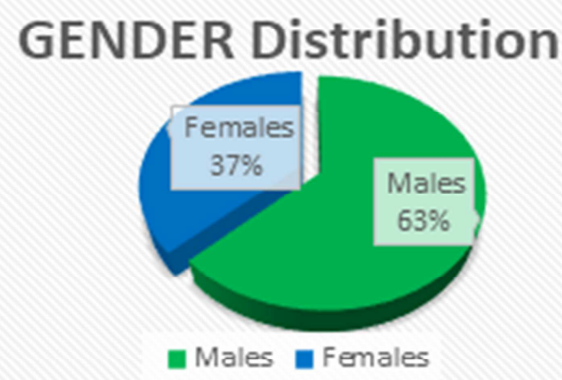

Figure 4: Pie chart showing gender distribution of patients in our study

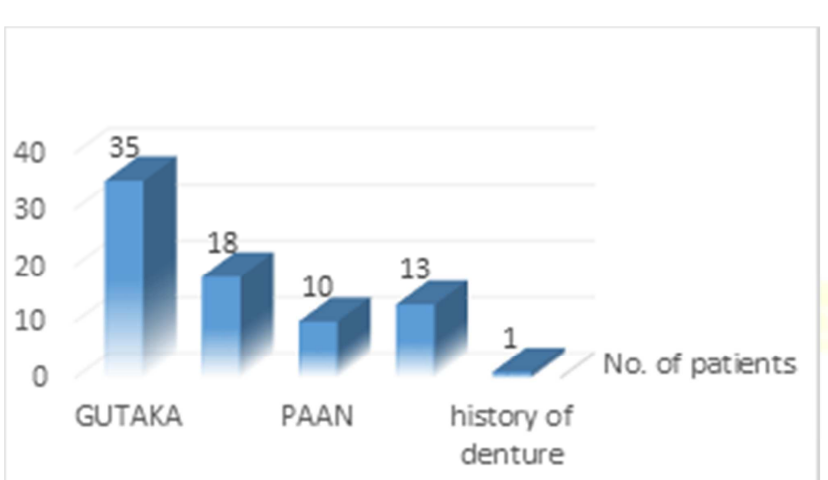

Figure 5: Bar chart showing risk factors of patients in our study

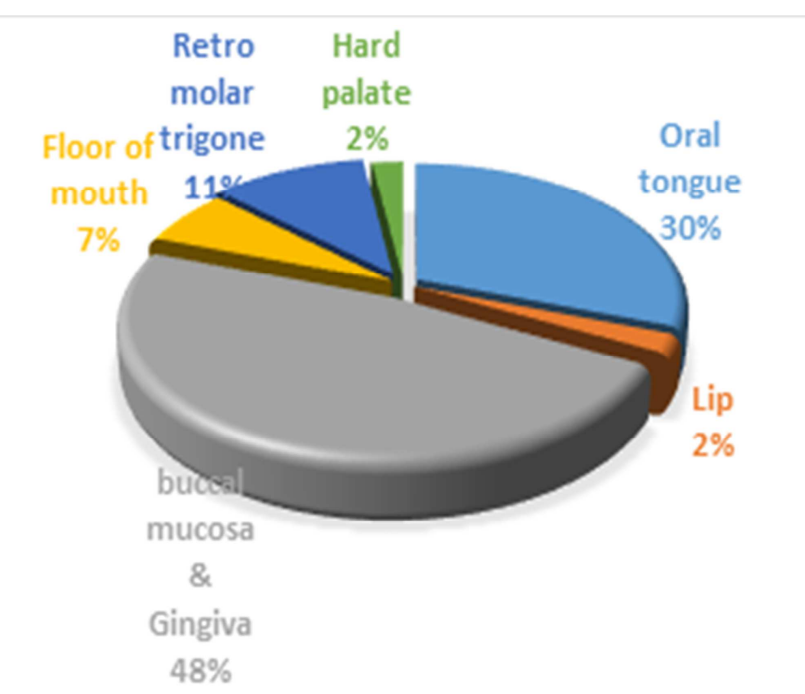

Figure 6: Pie chart showing location of oral cavity tumours in our study

\section{Tumor staging ( $T$ stage)}

We have observed that, CT scan correctly identified 31 out of 46 primaries i.e. $67.39 \%$ while attaining $15 \mathrm{FN}$ cases, giving a sensitivity of $67.39 \%$, PPV is $100 \%$. Whereas, MRI scans correctly identified 39 out of 46 primary tumors, while producing 7 false negatives cases, giving a sensitivity of $84.78 \%$. This data is statistically significant ( $p$ value $=0.0253$ ) making $\mathrm{CT}$ scan less sensitive modality than MRI scan in detection of primary tumor stage.

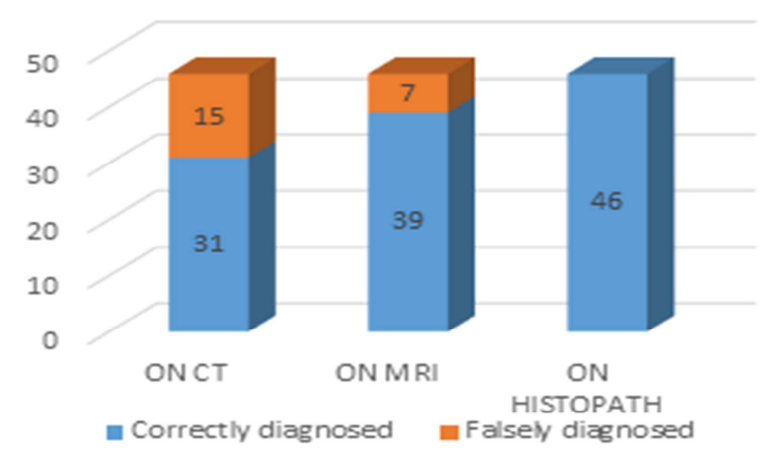

Figure 7: Bar chart showing correctly identified $\mathbf{t}$ staging on CT and MRI scan with respect to histopathological data

\section{Cervical lymph node metastasis}

Histopathological data of 22 patients i.e. $47.8 \%$ of patients showed positive neck nodes. The $\mathrm{CT}$ predicted positive neck nodes in 18 cases that included 14 TP cases and 4 FP cases. The CT predicted no neck nodes in 28 cases in which 21 are TP whereas 7 is FN. The sensitivity for MRI predicted is $66.67 \%$, specificity is $84.01 \%$, PPV is $77.78 \%$, NPV is $75.01 \%$ and accuracy is $76.09 \%$. Whereas, MRI predicted positive neck nodes in 21 cases that included 17 true positive cases and 4 false positive cases. The MRI predicted no neck nodes in 25 cases in which 21 are true negatives whereas 4 is false negative. The sensitivity for MRI predicted was $80.95 \%$, specificity is $84.01 \%$, PPV is $80.95 \%$, NPV is $84.01 \%$ and accuracy is $82.61 \%$. Chi square equals 0.401 with 1 degrees of freedom, $\mathrm{P}$ value equals 0.2634. The association is considered to be statistically not significant $(\mathrm{P}<0.05)$.

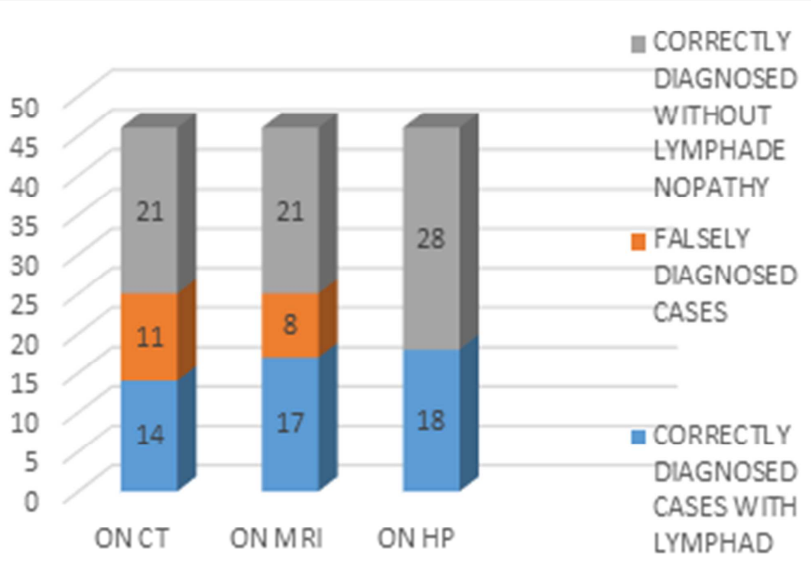

Figure 8: Bar chart showing correctly identified $\mathbf{n}$ staging on $\mathrm{CT}$ and MRI scan with respect to $\mathrm{h} / \mathrm{p}$

\section{Regional bony invasion}

We have observed that CT predicted bony invasion in 16 patients that included 13 were TP cases and 3 were FP cases. The CT scan predicted no bony invasion in 30 cases 
in which 24 were TN whereas 6 were FN. The sensitivity for $\mathrm{CT}$ scan in bony invasion by juxta-oral malignant tumors was $68.42 \%$, specificity was $88.89 \%$, PPV is $81.25 \%$, NPV is $80.01 \%$ and accuracy is $80.43 \%$. MRI predicted bony invasion in 18 patients that included 16 true positive cases and 2 false positive cases. The MRI predicted no bony invasion in 24 cases in which 20 are TN whereas 4 is FN. The sensitivity for MRI predicted bony invasion by juxta-oral malignant tumors was $80.01 \%$, specificity was $92.31 \%$, PPV is $88.89 \%$, NPV is $85.71 \%$ and accuracy is $86.84 \%$. Chi squared equals 0.187 with 1 degrees of freedom. The one-tailed $\mathrm{P}$ value equals 0.3329 is considered to be not statistically significant.

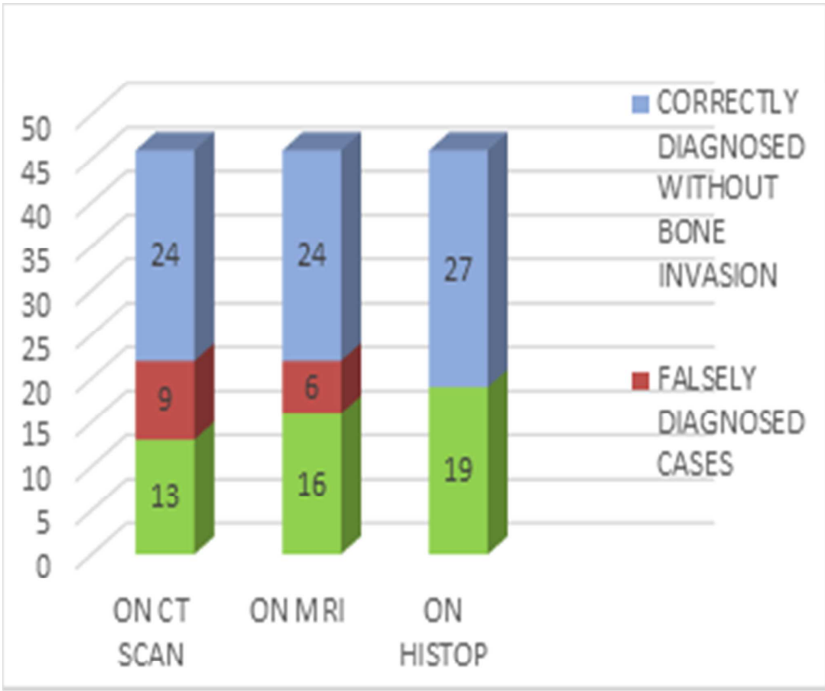

Figure 9: Bar chart showing correctly diagnosed regional bony invasion noted on CT and MRI scan with respect to histopathology

\section{Muscles of tongue invasion}

In our study, CT predicted muscles of tongue invasion in 12 cases that included 10 true positive cases and 2 false positive cases. The CT scan predicted no muscle of tongue invasion in 34 cases in which 24 were true negatives whereas 10 were false negative. The sensitivity for CT scan predicted muscles of tongue invasion by juxta-oral malignant tumors is $50.01 \%$, specificity is $90.31 \%$, PPV is $82.33 \%$, NPV is $70.59 \%$ and accuracy is $73.91 \%$. MRI predicted muscles of tongue invasion in 20 cases that included 17 true positive cases and 3 false positive cases. The MRI predicted no muscles of tongue invasion in 26 cases in which 24 are true negatives whereas 2 is false negative. The sensitivity for MRI predicted muscles of tongue invasion by juxta-oral malignant tumors is $89.47 \%$, specificity is $90.23 \%$, PPV is $85.61 \%$, NPV is $92.37 \%$ and accuracy is $89.13 \%$. Chi squared equals 3.067 with 1 degrees of freedom, one-tailed $\mathrm{P}$ value equals 0.0401 is considered to be statistically significant i.e. p value < $0.05 \%$.

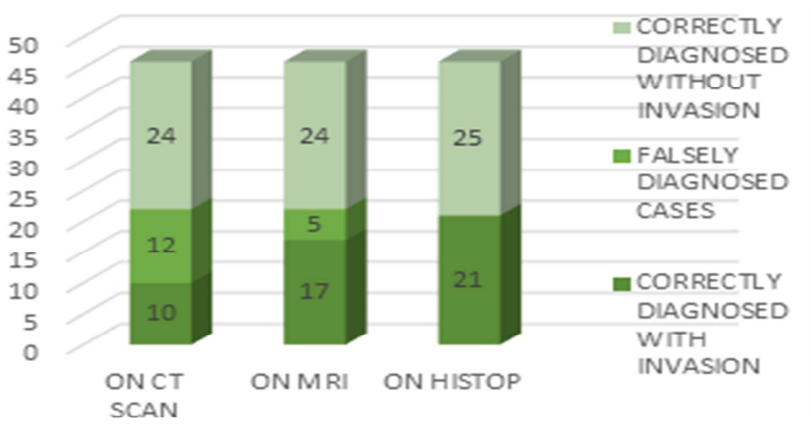

Figure 10: Bar chart showing correctly diagnosed muscles of tongue invasion noted on CT and MRI scan with respect to histopathology

\section{Case 1}

63 Yrs old female came with the history of swelling over right cheek with buccal mucosal ulceration since 6 months.
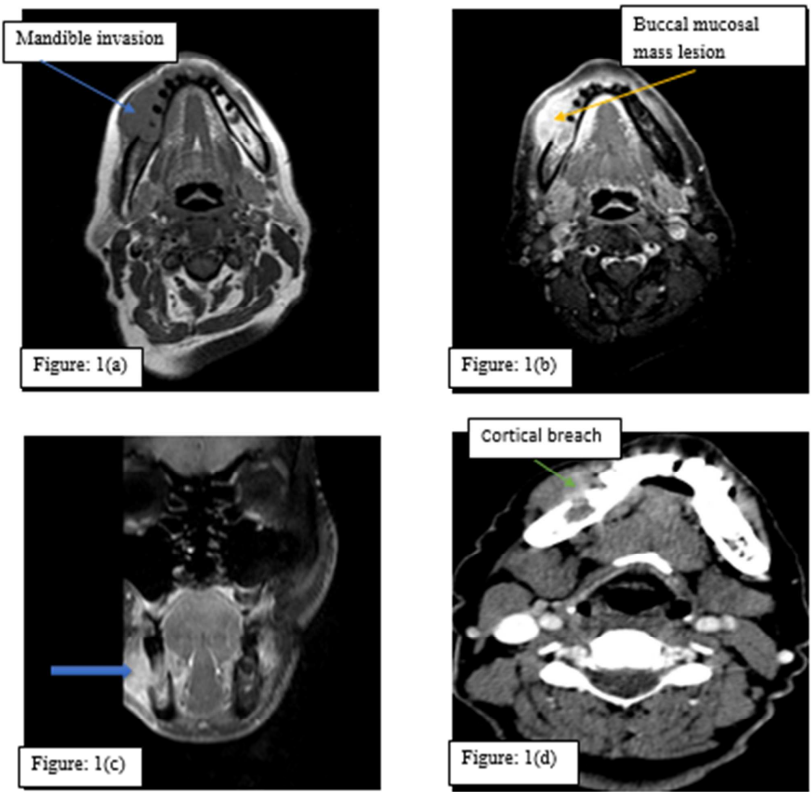

Figure: 1(a) axial T1 weighted pre contrast image showing hypo-intense to iso-intense right side buccal mucosa mass seen infiltrating in to mandible. Figure: $1(b) \&(c)$ axial and coronal T1 weighted fat suppressed post contrast image showing avid enhancement and mass is seen infiltrating in to mandible, arrow in (c). Fig: 1 (d) axial Contrast enhanced CT image showing right buccal mucosa mass seen infiltrating in to mandibular cortex as cortical breach(green arrow).

On HPE: Mass is proven to be squamous cell carcinoma of buccal mucosa. Also mass is showing bone (mandible) invasion on HPE.

Case 2

34 YRS male patient presented with complaints of ulcer over tongue left side since $1 \mathrm{yr}$ and with reduced tongue movement since 5-6 months with pain. 

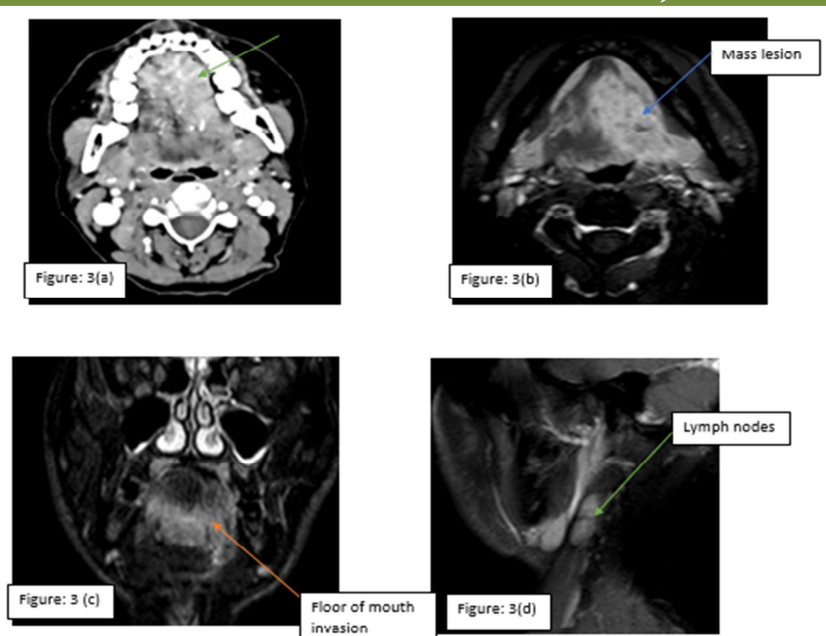

Figure 2: (a) axial contrast enhanced CT image showing heterogenous area of enhancement over tongue left side, mass is seen appearing not crossing midline. Figure 2: (b) \& (c) axial and coronal $\mathrm{T} 1$ weighted post contrast fat suppressed image showing heterogeneously enhancing mass lesion seen involving left side of tongue crossing midline and invading into floor of mouth. Figure 2:(d) sagittal T1 weighted post enhancement image showing right side level II lymph nodes.

On HPE: mass comes out as squamous cell carcinoma of tongue with extension in to floor of mouth muscles and no any bony invasion.

\section{Discussion}

In this study, 29(63.04\%) patients were male and $17(36.95 \%)$ of patients were females i.e. male-to-female ratio 1.71:1.Iype et al. reported male-to-female ratio of $(2.3: 1){ }^{[10]}$ Khandekar SP et al. (2006) have reported $49(61.25 \%)$ of the subjects were male while $31(38.75 \%)$ were females with male-to-female ratio (1.6:1). ${ }^{[11]} \mathrm{A}$ high proportion of cases among males may be due to the high prevalence of tobacco consumption habits among males. Moreover, tobacco is consumed in both chewing and smoking form in males predominantly in low socioeconomic groups, whereas in our society, less females indulged in tobacco smoking. ${ }^{[9]}$

In this study, study groups are divided into seven age groups with minimum age was 28 years and maximum age was 92 years. It was observed that maximum 13(28.26\%) patients were in the 51 to 60 years age group while age group 61 to 70 years constituting $9(23.6 \%)$ of patients. Johnson NW et al. (2011) found that the Oral cancer is usually a disease that occurs in males after the fifth decade of life. The mean age of presentation is in the fifth and sixth decade of life in Asian populations. ${ }^{[6]}$ Gangane et al. (2007), who have reported majority of the patients with OSCC in the age group of 50 to 59 years in there study. ${ }^{[7]}$ Although it is well $\square$ known that oral cancer is more prevalent in older age groups, but there is a recent trend of rising incidence of oral cancer in younger patients. ${ }^{[8,9]}$

Here, $22(47.8 \%)$ patients with malignant lesions were located to buccal mucosa \& gingiva and in 14 (31\%) patients lesions were of tongue. Khandekar et al. reported that buccal mucosa and alveolus was the most common site of oral cancer. ${ }^{[8]}$ Kandath $S$ et al. (2017) reported the most common site observed was buccal mucosa (41\%) followed by lower alveolus $(21 \%){ }^{[12]}$ The most common sites of OSCC were buccal mucosa and GBS followed by alveolus, and the findings are consistent with other studies. ${ }^{[6,12,13]}$ The tongue is considered as the most common site of occurrence of primary OSCCs in the developed countries, but in the developing countries, betel quid and/or tobacco chewing more commonly results in cancer of the buccal mucosa. ${ }^{[14,15]}$ This is mainly because of prolonged placement of the betel quid in the buccal pouch to obtain a maximum effect as the constituents of betel quid produce a sense of well-being and increased capacity to work by stimulation of parasympathetic nervous system. ${ }^{[15]}$

Most common risk factor is tobacco chewing 'Gutaka' in $35(76.08 \%)$ patients followed by tobacco smoke in 18 $(39.13 \%)$ patients. Chi AC et al. found that tobacco consumption is a major risk factor for oral and oropharyngeal SCC. ${ }^{[14]}$ Krishna A et al. found that there is a strong association between the use of smokeless tobacco and the risk of development of OSCC. ${ }^{[16]}$

In primary tumour staging, MRI scans correctly identified 39 out of 46 patients giving a sensitivity of $84.78 \%$. whereas CT scan correctly identified 31 out of 46 patients, giving a sensitivity of $67.39 \%$, making CT scanning less sensitive than MRI scanning in correctly identifying primary tumor of oral cavity. Bootz F. et al had studied 174 CT scans and 32 MRI examinations of oropharynx \& mouth carcinoma and he concluded that MRI is superior to CT in delineating tumor margins in $78 \%$ of patients. The Tstaging based on clinical \& CT findings was changed in only $5 \%$ of cases by MRI and the MRI is useful in T1staged tongue base carcinoma. MRI rather than CT should be used when dental fillings obscure the region of interest. ${ }^{[17]}$ El Kininy W et al. in their study of 54 patients noted that MRI scans correctly identified $37 / 54$ primary tumors, giving a sensitivity of $69 \%$. CT scanning correctly identified 25/54 primaries, giving a sensitivity of $46 \%$, making CT scanning less sensitive than MRI scanning in identifying primary tumors. ${ }^{[18]}$

Although, it is often difficult to differentiate metastatic from non-metastatic reactive nodes from CT and MR imaging, because the diagnosis of metastatic nodes is mainly based on measurement of nodal size. Whereas, other investigators give different values according to the location of lymph nodes. Other criteria used in the interpretation of $\mathrm{CT}$ and MR for staging lymph nodes include the presence of central necrosis, indistinct nodal margins, and more than one lymph node specially conglomerated. In our study, on postoperative histopathological data $47.8 \%$ of patients showed positive neck nodes $(\mathrm{n}=22)$. The sensitivity for MRI predicted was $80.95 \%$, and the specificity was $84.01 \%$. The sensitivity for CT predicted was $66.67 \%$, and the specificity was $84.01 \%$ however this difference is nonsignificant ( $\mathrm{p}$ value is not $<0.05$ ). Weiner et al. reported that detection of cervical lymph nodes involvement was similar for CT and MRI. In their study sensitivity and specificity of CT scan for cervical lymphadenopathy were $84.2 \%$ and $63.6 \%$ whereas for MRI sensitivity and specificity were $78.9 \%$ and $75.7 \%$ respectively. ${ }^{[20]}$ However both of these 
modalities were failed to detect small nodal metastasis. El Kininy W1 et al. reported that With regards to neck (nodal) disease/metastases, histology was only available for 34 of the 54 subjects, who underwent bilateral neck dissections. Of these 34 cases histology confirmed the presence of positive nodal disease in 19 of them. MRI scanning correctly identified 14 of 19 true positive nodal disease cases. This gives MRI scanning a sensitivity of $74 \%$. CT scanning identified positive nodes in 12 of 19 cases, producing a sensitivity of $63 \% .{ }^{[18]}$

In present study, the sensitivity for MRI predicted bony invasion by juxta-oral malignant tumors was $80.01 \%$, specificity was $92.31 \%$, PPV is $88.89 \%$, NPV is $85.71 \%$ and accuracy is $86.96 \%$. The sensitivity for CT scan in bony invasion by juxta-oral malignant tumors was $68.42 \%$ specificity was $88.89 \%$, PPV is $81.25 \%$, NPV is $80.01 \%$ and accuracy is $80.43 \%$. However this difference is nonsignificant ( $\mathrm{p}$ value is not $<0.05)$. Koopaie M. et al. $(n=30)$ in their study noted that sensitivity and specificity of CT scan was $50.00 \%$ and $85.00 \%$ and for MRI sensitivity and specificity was $90.00 \%$ and $85.00 \%$. $^{[21]}$ Wiener et al. reported that for $\mathrm{CT}$ scan sensitivity, specificity, Positive predictive value and Negative predictive value for bone invasion were $71.4 \%, 95.5 \%, 71.2 \%$ \& $95.5 \%$ respectively and for MRI sensitivity, specificity, Positive predictive value and Negative predictive value for bone invasion were $100 \%, 93 \%, 69.90 \%$ \& $100 \%$ respectively. ${ }^{[20]}$

In our study, the sensitivity for CT scan predicted muscles of tongue invasion by juxta-oral malignant tumors is $50.01 \%$, specificity is $92.31 \%$, PPV is $82.33 \%$, NPV is $70.59 \%$ and accuracy is $73.91 \%$. The sensitivity for MRI predicted muscles of tongue invasion by juxta-oral malignant tumors is $89.47 \%$, specificity is $88.89 \%$, PPV is $85.01 \%$, NPV is $92.37 \%$ and accuracy is $89.13 \%$. This difference is statistically significant $p$ value $<0.05$. Wiener et al. (2006) found sensitivity and specificity of CT'scan for muscle of tongue invasion was $72.7 \%$ and $61 \%$ respectively whereas, for MRI sensitivity and specificity was $81.8 \%$ and $63.4 \%$ respectively $(n=52) .{ }^{[20]}$

\section{Conclusion}

Management of oral cavity tumors is almost entirely dependent on stage of the disease, there is a need for reliable and accurate method for staging of the disease and thus for planning treatment. Radiological imaging serves as the ideal solution for staging of oral cavity malignancy.

Here it was concluded from our study that MRI was considered superior to CT scan in evaluating the primary tumor extent and muscle of tongue infiltration with significant statistical difference. CT and MRI are nearly similar in assessing cervical node metastasis. For bone invasion MRI is a superior over CT in our study, but this difference is not significant.

\section{References}

1. J. K. Elango, P. Gangadharan, S. Sumithra, and M. A. Kuriakose, "Trends of head and neck cancers in urban and rural India," Asian

\section{Pacific Journal of Cancer Prevention, vol. 7}

2. Manisha Sharma1, Manas Madan2, Mridu Manjari3, Tejinder Singh Bhasin4, Spriha Jain5, Saumil Garg6, "Prevalence of Head and Neck Squamous Cell Carcinoma (HNSCC) in our population: The clinicpathological and morphological description of 198 cases"

3. KenRussell Coelho1,2, "Challenges of the Oral cancer burden in India"

4. V. L. Allgar and R. D. Neal, "Sociodemographic factors and delays in the diagnosis of six cancers: analysis of data from the 'National Survey of NHS Patients: cancer'," The British Journal of Cancer, vol. 92, no. 11, pp. 1971-1975, 2005

5. Mohandas K Mallath*, David G Taylor*, Rajendra A Badwe, Goura K Rath, V Shanta, C S Pramesh, Raghunadharao Digumarti, Paul Sebastian, Bibhuti B Borthakur, Ashok Kalwar, Sanjay Kapoor, Shaleen Kumar, Jennifer L Gill, Moni AKuriakose, Hemant Malhotra, Suresh C Sharma, Shilin Shukla, Lokesh Viswanath, Raju T Chacko, Jeremy L Pautu, Kenipakapatnam S Reddy, Kailash S Sharma, Arnie D Purushotham, Richard Sullivan, "The growing burden of cancer in India: epidemiology and social context"

6. Singh MP, Kumar V, Agarwal A, Kumar R, Bhatt ML, Misra S, et al. Clinico-epidemiological study of oral squamous cell carcinoma: A tertiary care centre study in North India. J Oral Biol Craniofac Res 2016;6:31-4

7. Johnson NW, Jayasekara P, Amarasinghe AA. Squamous cell carcinoma and precursor lesions of the oral cavity: Epidemiology and aetiology. Periodontol 2000 2011;57:19-37

8. Gangane N,Chawla S,Anshu, Gupta SS,Sharma SM.reassesment of risk factors for oral cancer. Asian Pacific J Cancer Prev 2007;8:243-48

9. Khandekar SP, Bagdey PS, Tiwari RR. Oral cancer and some epidemiological factors: A hospital based study. Indian J Community Med 2006;31:157 $\square$ 9.

10. Iype EM,Pandey M ,Mathew A,Thomas G,Sebastian P,Nair MK.Oral cancer among patients under the age of 35 years.J Postgrad Med 2001;47:171-76

11. Kandath S, John B, Shobitha G. Oral cancer profile among patients who underwent oral biopsy in a tertiary referral center in Central Kerala. Indian J Multidiscip Dent [serial online] 2017 [cited 2019 Jan 29];7:14-20. Available from: http://www.ijmdent.com/text.asp?2017/7/1/14/209280,

12. Addala L, Pentapati CK, Reddy Thavanati PK, Anjaneyulu V, Sadhnani MD. Risk factor profiles of head and neck cancer patients of Andhra Pradesh, India. Indian J Cancer 2012;49:215-9.

13. Shenoi R, Devrukhkar V, Chaudhuri, Sharma BK, Sapre SB, Chikhale $\mathrm{A}$, et al. Demographic and clinical profile of oral squamous cell carcinoma patients: A retrospective study. Indian J Cancer 2012;49:216.

14. Chi AC, Day TA, Neville BW. Oral cavity and oropharyngeal squamous cell carcinoma - An update. CA Cancer J Clin 2015;65:401-21.

15. Madani AH, Dikshit M, Bhaduri D, Jahromi AS, Aghamolaei T Relationship between selected socio-demographic factors and cancer of oral cavity - A case control study. Cancer Inform 2010;9:163-8.

16. Gupta B, Johnson NW. Systematic review and meta-analysis of association of smokeless tobacco and of betel quid without tobacco with incidence of oral cancer in South Asia and the pacific. PLoS One 2014;9:e113385

17. Bootz F, Lenz M., Skalej M, Bongers H. Computed tomography (CT) and magnetic resonance imaging (MRI) in T-stage evaluation of oral and oropharyngeal carcinomas.Clin Otolaryngol 1992; 17: 421-429

18. El Kininy W, Israr M, Toner M, Meaney J, Stassen LFA (2017) Prospective Comparison of CT scan, MRI and PET/CT in the Diagnosis of Oral Cancer and Nodal Metastasis. Int J Surg Res Pract 4:050.doi.org/ 10.23937/2378-3397/1410050

19. Wiener, E., et al., Comparison of 16-slice MSCT and MRI in the assessment of squamous cell carcinoma of the oral cavity. European journal of radiology, 2006. 58(1):p. 113-118

20. M Koopaie, N Hoshiary Comparison of CT scan and MRI Findings in the Assessment of Squamous Cell Carcinoma,Journal of Mazandaran University of Medical Sciences 24 (116), 205-21 


\section{Saxcena et al; Oral Cavity Squamous Cell Carcinama}

Copyright: (C) the author(s), publisher. Asian Journal of Medical Radiological Research is an Official Publication of "Society for Health Care \& Research Development". It is an open-access article distributed under the terms of the Creative Commons Attribution Non-Commercial License, which permits unrestricted non-commercial use, distribution, and reproduction in any medium, provided the original work is properly cited.

How to cite this article: Saxena S, Gupta A, Meena D, Khokhar H, Lal B, Godara C. Oral Cavity Squamous Cell Carcinoma Comparitive Evaluation on Computed Tomography and Magnatic Resonance Imaging. Asian J. Med. Radiol. Res. 2019;7(1):61-67.

DOI: dx.doi.org/10.21276/ajmrr.2019.7.1.14

Source of Support: Nil, Conflict of Interest: None declared. 